\title{
Coronavirus-Like Particles in Nonhuman Primate Feces
}

\author{
By \\ G. C. Smith, T. L. Lester, R. L. Heberding, and S. S. Kalter \\ Department of Microbiology and Infectious Diseases, \\ Southwest Foundation for Research and Education, \\ NIH and WHO Collaborating Center for Reference and Research in Simian Viruses, \\ San Antonio, Texas, U.S.A. \\ With 2 Figures
}

Accepted December 29, 1981

\begin{abstract}
Summary
Coronavirus-like particles were detected by electron microscopy in normal and diarrhea stool specimens from baboons, chimpanzees, macaques, and marmo. sets. There was a high prevalence of particles in both normal and diarrhea stools of older animals, whereas stools from nonweaned animals rarely contained these coronavirus-like particles.
\end{abstract}

\section{Introduction}

A number of infectious agents are responsible for the clinical condition "diar"rhea" or "gastroenteritis". In certain instances the etiology is known, i.e., various organisms such as bacteria, parasites, or viruses, but the specific cause of the vast majority of this entity is still unknown. Several viral agents other than those previously recognized are suspected and a number of laboratories are engaged in examining the possible relationship of viruses to gastroenteritis. In our attempts to establish an animal model for studies of this disease, we have been examining the nonhuman primate to ascertain what viruses may be found in the intestinal tract of "normal" animals as well as animals with diarrhea $(14,15)$. Of the various viruses currently suspected of being etiologically associated with this syndrome, rotaviruses, coronaviruses and the Norwalk agent are leading candidates. In a previous study we did not find electron microscopic evidence for a relationship with the rotaviruses (15). Inasmuch as there was some evidence for the presence of coronaviruses in these animals, we turned our attention to this group of agents.

Coronaviruses or coronavirus-like particles have been observed in a variety of animal feces including that from birds, calves, pigs, cats, dogs, rodents (23), foals $(2)$, humans $(3,5)$ and simians $(1,4,16)$. Coronaviruses have also been shown to cause gastroenteritis in rodents (18), calves $(20)$, and pigs $(9,22)$. In this report we describe our findings with coronaviruses in various species of nonhuman primates. 


\title{
Materials and Methods
}

\begin{abstract}
Animals
Nonhuman primates (Table 1) derived from a number of primate facilities as well as from this laboratory were employed. The conditions under which these animals were maintained have been previously described (13). Specimens were obtained from weaned and nonweaned animals which were either "normal" or had observable diarrhea. Animal ages ranged from newborns to relatively old animals and included both sexes.

Animal ages was taken into consideration and each individual was categorized as infant, juvenile, or adult. Housing of each species and animal varied depending on the program to which that animal was allocated. One male and 3 or 4 female chimpanzees were routinely housed together, with the male being removed when offspring were born. Infants were removed from female parents at 6 to 8 months of age and grouped in gang cages, each having access to the stool of all others. Some baboons were housed 1 or 2 males with 20 breeder females. Offspring were not removed and had access to feces of cagemates. Marmosets and macaques were weaned and paired for breeding (with their respective species) at 5 months. In some instances, these nonhuman primates were housed singly, but for the most part, they were typically housed with others. Therefore many animals had ample opportunity for fecal exposure.
\end{abstract}

\section{Electron Microscopy}

Fecal suspensions, about 20 percent $(\mathrm{v} / \mathrm{v})$, in phosphate buffered saline were clarified in a Sorval RC2B centrifuge at $5000 \times g$ for 30 minutes to eliminate bacteria and debris. The supernatant fluids were then ultracentrifuged in a Spinco $50 \mathrm{Ti}$ fixed angle rotor at $32,000 \mathrm{rpm}$ for 1 hour. The resulting pellet was resuspended in $0.05 \mathrm{ml}$ of distilled $\mathrm{H}_{2} \mathrm{O}$. One or more drops of the suspension were applied to Formvar-coated copper grids and excess fluids were removed by touching filter paper to grid edges. Some grids were washed with one or more drops of distilled water and all were exposed to 1 percent phosphotungstic acid (PTA) at $\mathrm{pH} 2,5$, or 7 . All specimens were exposed to an ultraviolet light emitting lamp $\left(30,000 \mathrm{ergs} / \mathrm{sec} / \mathrm{cm}^{2}\right)$ for 5 minutes at a distance of $10 \mathrm{~mm}$, and were examined with an AEI EM6B electron microscope.

\section{Results}

Table 1 indicates the specimens examined for the presence of virus particles in diarrhea and normal stool samples. Of 108 samples, 46 contained coronaviruslike particles. Of these 46 , mixed infection was found once with a herpesvirus, once with an adenovirus, and once with a picornavirus. The 62 coronavirusnegative samples yielded an adenovirus and a herpesvirus once each in different animals. Coronavirus-like particles were noted in 49 percent $(19 / 39)$ of the diarrhea and 38 percent $(27 / 69)$ of the normal stools. When age was considered, 3 of 45 infants, 21 of 24 juveniles, and 18 of 21 adult nonhuman primates had coronaviruslike particles (Table 1). Table 2 provides a comparison of feces from weaned and nonweaned simians for the presence of coronavirus-like particles.

Followup stool samples were obtained from four animals. Samples from an infant chimpanzee and two infant baboons (initially normal and then when they had diarrhea) were all negative for coronavirus-like particles. One normal stool from a 2-month-old infant baboon also did not have detectable viruses, but was found positive for coronavirus-like particles when the animal had diarrhea at 4 months of age. The only adult baboon resampled possessed coronavirus-like particles in both a diarrhea stool specimen and the followup normal stool specimen.

The particles found in diarrhea and normal feces were typical of coronaviruses (Fig. 1) and ranged from $80-190 \mathrm{~nm}$ inclusive of surface projections $(16-25 \mathrm{~nm})$. 
Table 1. Comparison of various nonhuman primate feces for the presence of coronavimuslike particles

\begin{tabular}{|c|c|c|c|c|c|}
\hline Animal & Age & Stoola & $\begin{array}{l}\text { No corona- } \\
\text { virus-like } \\
\text { particles }\end{array}$ & $\begin{array}{l}\text { Corona- } \\
\text { vimus-like } \\
\text { particles }\end{array}$ & $\begin{array}{l}\text { Other } \\
\text { viruses }\end{array}$ \\
\hline \multicolumn{6}{|l|}{ Baboon } \\
\hline \multirow[t]{2}{*}{ P. hamadryas } & Infant & $\mathrm{D}$ & 2 & 0 & \\
\hline & Infant & $N$ & 1 & 0 & \\
\hline \multirow[t]{6}{*}{ P. cynocephalus } & Infant & $\mathrm{D}$ & 10 & 1 & Adeno \\
\hline & Juvenile & $\mathrm{N}$ & 0 & 6 & \\
\hline & Infant & $\mathrm{N}$ & 10 & 1 & \\
\hline & Adult & $\mathrm{D}$ & 0 & 6 & Adeno \\
\hline & Adult & $\mathrm{N}$ & 0 & 5 & Picorna \\
\hline & Unknown & $\mathrm{N}$ & 1 & 1 & \\
\hline \multicolumn{6}{|l|}{ Chimpanzee } \\
\hline \multirow[t]{6}{*}{ Pan sp. } & Infant & $\mathrm{D}$ & 4 & 0 & \\
\hline & Intant & $\mathrm{N}$ & 10 & 1 & \\
\hline & Juvenile & $\mathrm{D}$ & 1 & 1 & \\
\hline & Juvenile & $\mathbf{N}$ & 1 & 2 & Herpes \\
\hline & Adult & $N$ & 1 & 5 & \\
\hline & Unknown & $\mathrm{N}$ & 5 & 1 & \\
\hline \multicolumn{6}{|l|}{ Macaque } \\
\hline \multirow[t]{3}{*}{$M$. nemestrina } & Infant & $\mathrm{N}$ & 4 & 0 & Picoma \\
\hline & Juvenile & $\mathrm{N}$ & 0 & 2 & \\
\hline & Adult & $\mathrm{N}$ & 0 & 1 & \\
\hline \multirow[t]{2}{*}{$M$. tascicularis } & Juvenile & $\mathrm{X}$ & 1 & 0 & \\
\hline & Unknown & $\mathrm{N}$ & 0 & 1. & \\
\hline \multirow[t]{4}{*}{ M. mulatta } & Infant & $\mathrm{D}$ & 1 & 0 & \\
\hline & Tuvenile & $\mathrm{D}$ & 0 & 10 & \\
\hline & Unlmnown & $\mathrm{N}$ & 3 & 0 & \\
\hline & Unknown & $\mathrm{D}$ & 2 & 1 & \\
\hline \multicolumn{6}{|l|}{ Marmoset } \\
\hline S. oedipus & Adult & $\mathbf{N}$ & 0 & 1 & \\
\hline S. fuscicollis & Adult & $\mathrm{N}$ & 1 & 0 & \\
\hline O. jacchus & Adult & $\mathbf{N}$ & 1 & 0 & \\
\hline \multicolumn{6}{|l|}{ Capuchin } \\
\hline C. apella & Unknown & $\mathbf{N}$ & 3 & 0 & \\
\hline
\end{tabular}

* $\mathrm{D}=$ diarrhea, $\mathrm{N}=$ normal

Table 2. Comparison of feces from weaned and nonweaned simians for the presence of coronavirus-like particles

\begin{tabular}{llcc}
\hline & \multicolumn{3}{c}{ Presence of coronavirus-like particles } \\
\cline { 2 - 4 } & Infant and Juvenile stools & \\
\cline { 2 - 4 } & Nonweaned & Weaned & Adult stools \\
\hline Baboon & $1 / 23^{\circ}$ & $7 / 8$ & $11 / 11$ \\
Chimpanzee & $0 / 7$ & $3 / 13$ & $5 / 6$ \\
Macaque & $0 / 5$ & $13 / 13$ & $1 / 1$ \\
Marmoset & NT & NT & $1 / 3$ \\
\hline
\end{tabular}

a Numerator $=$ number positive, denominator $=$ number sampled

b $\mathrm{NT}=$ not tested 
These projections (spherical or teardrop-like knobs attached to thin stalks) radiated from the surface of the particles. Dumbbell-shaped, elongated particles (about $100 \times 300 \mathrm{~nm}$ ), and a variety of other configurations were detected and PTA occasionally penetrated these particles. It is noted that cornavirus subgroups may exist based on projection morphology $(4,8)$. The pleomorphic nature of coronaviruses is great and the coronavirus-like particles reported here are no exception.

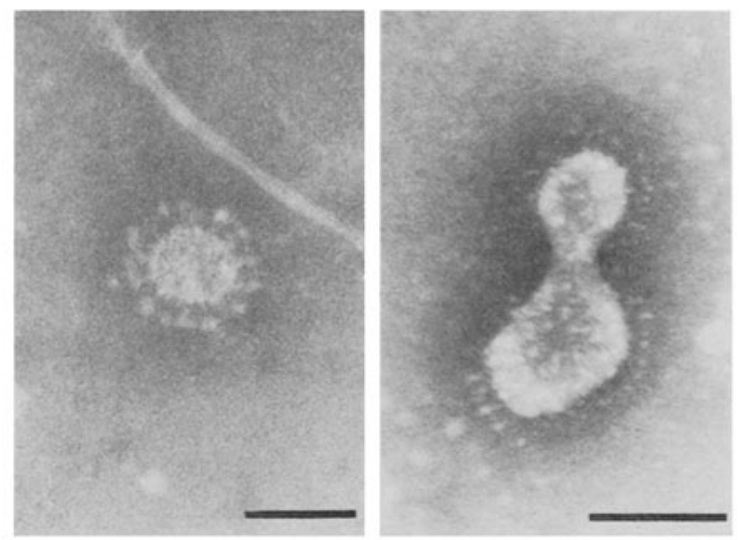

Fig. 1. Coronavirus-like particles in nonhuman primate feces. Scale $=100 \mathrm{~nm}$

An unidentified particle type (Fig. 2) was rarely encountered and was somewhat similar to the coronavirus-like particles reported here. General shape was the same but dimensions were frequently larger (up to $700 \mathrm{~nm}$ ). These particles did not have teardrop-shaped knobs on projections, but had filament-like projections radiating from the particle which were attached to a single membranelike structure apparently encircling the particle. These were found in both normal and diarrhea specimens.

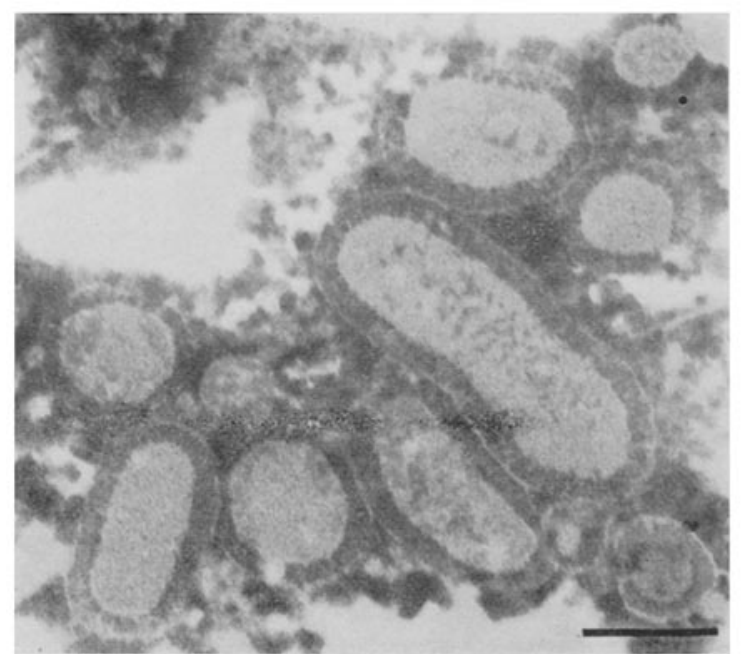

Fig. 2. Unidentified particle in nonhuman primate feces. Scale $=100 \mathrm{~nm}$ 


\section{Diseussion}

In the course of studies attempting to define the viral etiology of diarrhea in nonhuman primates housed either at this facility or sent to us from others, we have found several virus types including coronavirus-like particles, adenoviruses, herpesviruses, picornaviruses (14), and numerous bacteriophage types (15) associated with both normal fecal and diarrhea specimens. Since some of our nonhuman primates were housed in pairs or in gangcages, it is difficult to say with certainty that all fecal specimens were always from a particular animal; however, in most of these instances the ages of the animals were closely matched.

Coronavirus-like particles were observed in 1 of 18 infant, 11 of 12 juvenile, and 6 of 6 adult diarrhea specimens, and in 2 of 27 infant, 10 of 12 juvenile, and 12 of 15 adult normal stools thus generally indicating lack of association of coronavirus-like particles with diarrhea. A similar situation has been reported in cats (12), dogs (19), humans (6), cynomolgous and rhesus monkeys (4). Adenoviruses, picornaviruses, and herpesviruses were encountered occasionally but rotaviruses, caliciviruses, and astroviruses have not yet been detected in our colony (15). Simian adenoviruses were recovered from a high percentage of rhesus monkeys with diarrhea although the etiologic relationship was questioned (21).

Early electron microscopic viral flora studies of human stools (11) did not indicate these coronavirus-like particles or reflected uncertainty as to the viral nature of these particles (17), but more recent studies have indicated their persistent excretion (6). Our previous studies of nonhuman primate stools (15) also revealed these coronavirus-like particles; however, their pleomorphic nature compounded by the presence of the very large but similar unidentified particle types (Fig. 2) precluded reference to these coronavirus-like particles as viruses at that time. Furthermore, their presence in both normal and diarrhea stools clouded the issue.

Initial attempts using Vero cells to isolate these coronavirus-like particles from stool filtrates of four normal adult baboons were unsuccessful. The cultures in each case were lost due to an overgrowth of a picornavirus isolate as determined by characteristic haematoxylin and eosin cytopathic staining patterns.

The data reported herein suggest a positive relationship between the presence of coronavirus-like particles and older animals, whereas infants rarely possessed these particles. Others have reported that particles resembling coronaviruses are not found in Indian neonates, but are found in older children and adults (17). "It might be assumed that coronaviruses are not as highly infectious or perhaps not as stable as rotaviruses; therefore, in countries where fecal-oral transmission does not occur so readily, infection is found in an older age group" (10).

Our cumulative data show that 3 of 45 infants, 21 of 24 juveniles, and 18 of 21 adult nonhuman primates possessed coronavirus-like particles in their feces (either normal or diarrhea). Of our infants and juveniles, 1 of 35 nonweaned and 23 of 34 weaned animals had detectable coronavirus-like particles (Table 2). These data support the theory that the process of weaning may be related to the likelihood of infection with coronavirus-like particles. Furthermore, many of the infants in this study had access to colostrum which may prevent infection with coronavirus-like particles. It is well known that colostrum contains antibodies and possibly mediators of cell mediated immunity (24). The percentage incidence 
of particles in feces from weaned animals was high for each species examined except chimpanzees. Even though these chimpanzees, which lacked detectable virus, were between 9 months and 4 years old, it is possible that when weaned and grouped with similar aged animals (6-8 months) they did not come into contact with the virus. It is also possible that the half-life of chimpanzee colostral antibodies is longer than typical and that antibody persisted in their serum ( 7 , 24).

In conclusion, 43 percent of all primate stools from our colony were found possessing coronavirus-like particles. Viral presence did not appear related to gastroenteritis but was associated more frequently with older animals. In addition, infection or persistent excretion seems to be more likely after weaning. The significance of these particles and their relationship to gastroenteritis, transmission, and coronaviruses warrants further study.

\section{Acknowledgments}

We wish to thank Mr. A. Bodenman for his able technical assistance. These studies were supported in part by grants RR 00361 from the National Institutes of Health, Bethesda, Md., and V 4/181/38 from the World Health Organization.

\section{References}

1. Ashrey, C. R., Caul, E. O., Clarke, S. K. R., Corner, B. D., Dunn, S.: Rotavirus infections of apes, Lancet $2,477(1978)$.

2. Bass, E. P., Sharpere, R. L.: Coronavirus and gastroenteritis in foals. Lancet 2 , $822(1975)$.

3. CAUL, E. O., Clarke, S. K. R.: Coronavirus propagated from patient with nonbacterial gastroenteritis. Lancet 2, 953-954 (1975).

4. Caul, E. O., Egglestone, S. I.: Coronavirus-like particles present in simian. faeces. Vet. Rec. 104, $168-169$ (1979).

5. Caul, E. O., Paver, W. K., Clarke, S. K. R.: Coronavirus particles in faeces from patients with gastroenteritis. Lancet 1, 1192 (1975).

6. Clarke, S. K. R., CaUl, E. O., Egglestone, S. I.: The human enteric coronaviruses. Postgrad. Med. J. 55, 135-142 (1979).

7. Curtis, J., Bourne, F. J.: Half-lives of immunoglobulins IgG, IgA and IgM in the serum of new-born pigs. Immunology 24, 147-155 (1973).

8. Davies, H. A., Macnaugrton, M. R.: Comparison of the morphology of three coronaviruses. Areh. Virol. 59, 25-33 (1979).

9. Doyle, L. P., Hutchings, L. M.: A transmissible gastroenteritis in pigs. J. Am. Vet. Assoe. 108, 257-259 (1946).

10. Flewett, T. H.: Electron microscopy in the diagnosis of infectious diarrhea. J. Am. Vet. Mod. Assoc. 173, 538 - 543 (1978).

11. Flewett, T. H., Bryden, A. S., Davies, Heather: Diagnostic electron microscopy of faeces. I. The viral flora of the faeces as seen by electron microscopy. J. Clin. Pathol. 27, 603 -608 (1974).

12. Hoshiso, Y., Scont, F. W.: Coronavirus-like particles in the feces of normal eats. Arch. Virol. 63, 147-152 (1980).

13. Kalter, S. S.: The baboon: microbiology, clinical chemistry and some hematological aspects. Primat. Med. 8, 1-171 (1973).

14. Kalter, S. S., Heberdive, R. L., Fresd, J.: Isolation of an enterovirus (SV 19) from baboons (Papio eynocephalus). Lab. Anim. Sci. 31, 190-191 (1981).

15. Kalter, S. S., Smith, G. C., Heberling, R. L.: Electron microscopic examination. of primate feces for rotaviruses. Lab. Anim. Sci. 29, 516-518 (1979). 
16. Majer, M., Behrens, F., Weinmand, E., Mauler, R., Maass, G., Baumeister; H. B., LuthardT, T.: Diarrhea in newborn cynomolgus monkeys infected with human rotavirus. Infection 6, $71-72$ (1978).

17. Mathan, M., Mathay, V. I., Swamtnathan, S. P., Yesudoss, S., Baker, S. J.: Pleomorphic virus-like particles in human faeces. Lancet 1, 1068-1069 (1975).

18. Rowe, W. P., Harteky, J. W., CapPs, W. I.: Mouse hepatitis virus infection as a highly contagious, prevalent, enteric infection of mice. Proc. Soc. Exp. Biol. Med. 112, 161-165 (1963).

19. Schnaqu, R. D., Holmes, I. H.: Coronavirus-like particles in stools from dogs, from some country areas of Australia. Vet. Rec. 102, 528-529 (1978).

20. Statr, E. L., Rhodes, M. B., White, R. G., Mebus, C. A.: Neonatal calf diarrhea: Purification and electron microscopy of a coronavirus-like agent. Am. J. Vet. Res. 33, 1147-1156 (1972).

21. Stuker, G., Oshroo, L. S., Schmot, N. J., Holmbert, C. A., Anderson, J. H., Guaser, C. A., Henriokson, R. V.: Virus detection in monkeys with diarrhea: The association of adenoviruses with diarrhea and the possible role of rotaviruses. Lab. Anim. Sci. 29, 610-616 (1979).

22. TaJTMA, M.: Morphology of transmissible gastroenteritis virus of pigs: A possible member of coronaviruses. Arch. Virol. 29, 105-108 (1970).

23. Tyrrell, D. A. J., Alexander, D. J., Almeida, J. D., Cunningham, C. H., Easterday, B.C., Garwes, D.J., Hierholzer, J.C., Kaptudan, A., MacNaugmton, M. R., McIntosh, K.: Coronaviridae: Second Report. Intervirology 10, 321-328 (1978).

24. WrtmmanN, G., JakUBiK, J.: Colostral immunity in piglets from sows vaccinated with inactivated Aujeszky disease virus vaccine. Arch. Virol. 60, 33-42 (1979).

Authors' address: Dr. G. C. Smrth, Department of Microbiology and Infectious Diseases, Southwest Foundation for Research and Education, P.O. Box 28147, San Antonio, TX 78284, U.S.A.

Received August 11, 1981 